\title{
The Level of Workplace Bullying and Its Impact on Employee Loyalty: An Applied Study on the Nursing Staff at Menoufia University Hospitals
}

\author{
Ahmed Ebrahim Mousa ${ }^{1}$ \\ ${ }^{1}$ Assistant Professor of Business Administration in Faculty of Commerce, Menoufia University, Egypt \\ ${ }^{2}$ Assistant Professor of HRM in Academic Programs for Military Colleges, Abu Dhabi University, UAE \\ Correspondence: Ahmed Ebrahim Mousa, Assistant Professor of Business Administration, Faculty of \\ Commerce, Menoufia University, Egypt.
}

Received: December 18, 2020

Accepted: January 28, 2021

Online Published: February 8, 2021

doi:10.5539/ibr.v14n3p1

URL: https://doi.org/10.5539/ibr.v14n3p1

\begin{abstract}
The aim of this study is to conduct an examination of how workplace bullying affects employee loyalty. The focus of the study was technical and specialist nurses employed in Egypt's Menoufia University. The study's data was collected from 240 participants. The results from the study show that the sub-dimensions of workplace bullying and correlations with employee loyalty are moderate in the negative direction. On the other hand, it has also been concluded that the perceptions of workplace bullying sub-dimensions explain 23.8 percent of the aggregate variance in employee loyalty. The analysis of the teats results of regression coefficient regression model is conducted, it can be noted that as the levels of workplace bullying increase in the workplace, the perception of employee loyalty statistics decreases. When it comes to comparative importance predictor variables on the levels of employee loyalty shows that the leading factor is attacks on health, the second is attacks on self-expression, the third is attacks on social relations, and the last is attacks on reputation. In the study, the insignificance sub-dimension, which has the least average is the attack on the quality of professional and personal life. From the results, it can be concluded that the nursing staff at Menoufia University Hospital's perception of their loyalty variable is at the level of medium.
\end{abstract}

Keywords: employee loyalty, organizational climate, workplace bullying

\section{Introduction}

Since the middle years of the $19^{\text {th }}$ Century, the area of loyalty or organizational commitment has attracted the attention of several researchers (Ibrahim \& Al Falasi, 2014). The satisfaction and loyalty of employees are perceived as a vital element regarding the capacity of organizations in the service sector to meet the needs of their customers (Silvestro, 2002). Notwithstanding the reality that job satisfaction denotes a response that is effective to the precise elements of a job and the attitudes of employees towards that job, employee satisfaction, on the other hand, is seen by Chen (2006) as denoting the actual response to the entire organization. From empirical evidence, it can be concluded that job satisfaction is a harbinger to employee organizational loyalty (Turkyilmaz et al., 2011). For Chen (2006), such an observation implies that job satisfaction is the basis on which employee loyalty is founded, to the extent that loyalty acts as a mediator to the impact of satisfaction on turnover variables.

The World Health Organization is cited by Georgakopoulos and Kelly (2017, p. 450) defining a healthy workplace in the following way:

A healthy workplace is a place where everyone works together to achieve an agreed vision for the health and well-being of workers and the surrounding community. It provides all members of the workforce with physical, psychological, social, and organizational conditions that protect and promote health and safety. It enables managers and workers to increase control over their own health and to improve it, and to become more energetic, positive and contented.

Studies into workplace bullying emerged from research into school bullying, which became common in the Scandinavian countries in the later years of the 1980s (Rai \& Agarwal, 2018a). The German-born physician and 
psychiatrist, Heinz Leymann (1990) have come to be seen as the father of this field. His initial interest was in school bullying. He later expanded it to the workplace. In the U.K., the topic as introduced by a freelance journalist on the 1990s. His name is Andrew Adams (1992) and is credited with coining the word bullying (Rai \& Agarwal, 2017).

Since its early days, Workplace bullying (WPB) has become recognised as a crucial social challenge for close to forty years now (Salin \& Notelaers, 2017). Studies indicated that employees in the health sector like personal carers and nurses tend to experience higher levels of WPB when compared to employees in other fields. De Cieri et al. (2019) cites Spector et al. (2014) who conducted an international review and came to the conclusion that 37 percent of nurses reported that they had been victims of WPB.

Chadwick and Travaglia (2017) report that at a global level, workplace bullying prevalence levels differ significantly. This is an observation acknowledged by Broome and Williams-Evans (2010) who concluded that the lowest levels were 3.5 percent in Sweden. On the other hand, Bryant et al. (2009) observe that the highest level of WPB is in the USA, where it sits at 21.5 percent. Reports from the U.K. indicate that reported rates of WPB sit at 15 percent (Balducci et al., 2009). In the last 15 or so years, there has been a proliferation of literature on bullying to the extent that the filed has now been placed within the common vocabulary in human resources management (HRM) field (Rai \& Agarwal, 2018a). This paper tries to answer the following question: what is the impact of the level of workplace bullying on employee loyalty? The aim of this study is to conduct an examination of how workplace bullying affects employee loyalty on the Nursing Staff at Menoufia University Hospitals.

\section{Theoretical Background}

This section will deliver a definition and discussion of the character of workplace bullying and employee loyalty. It will then present the research model and proposed hypothesis regarding the impact of workplace bullying practices.

\subsection{Employee Loyalty}

According to Turkyilmaz et al. (2011), loyalty is shown by an individual's strong willingness to remain a member of an organization. Hence, it can play a positive role in an organization's ability to retain its members. There seems to be an agreement between the economic and management literature with regards to the positive impact of loyalty for organizational performance (Guillon \& Cezanne, 2014). This is a view also acknowledged by Rice et al. (2017) who say that employee loyalty is generally perceived as an explicitly positive characteristic at both the collective and individual level. Even with this being said, it remains clear that this connection still needs to be investigated, since there is still no agreement on what the concept of loyalty denotes (Guillon \& Cezanne, 2014). Numerous ideas have been proposed with the aim of characterising employee loyalty. Some of the words that practitioners and scholars have played around with include, trust, attachment, identification, commitment, and participation (Guillon \& Cezanne, 2014).

Kamnerdkarn (2010) identified five dimensions of employee loyalty (Figure 1) as discussed below: 


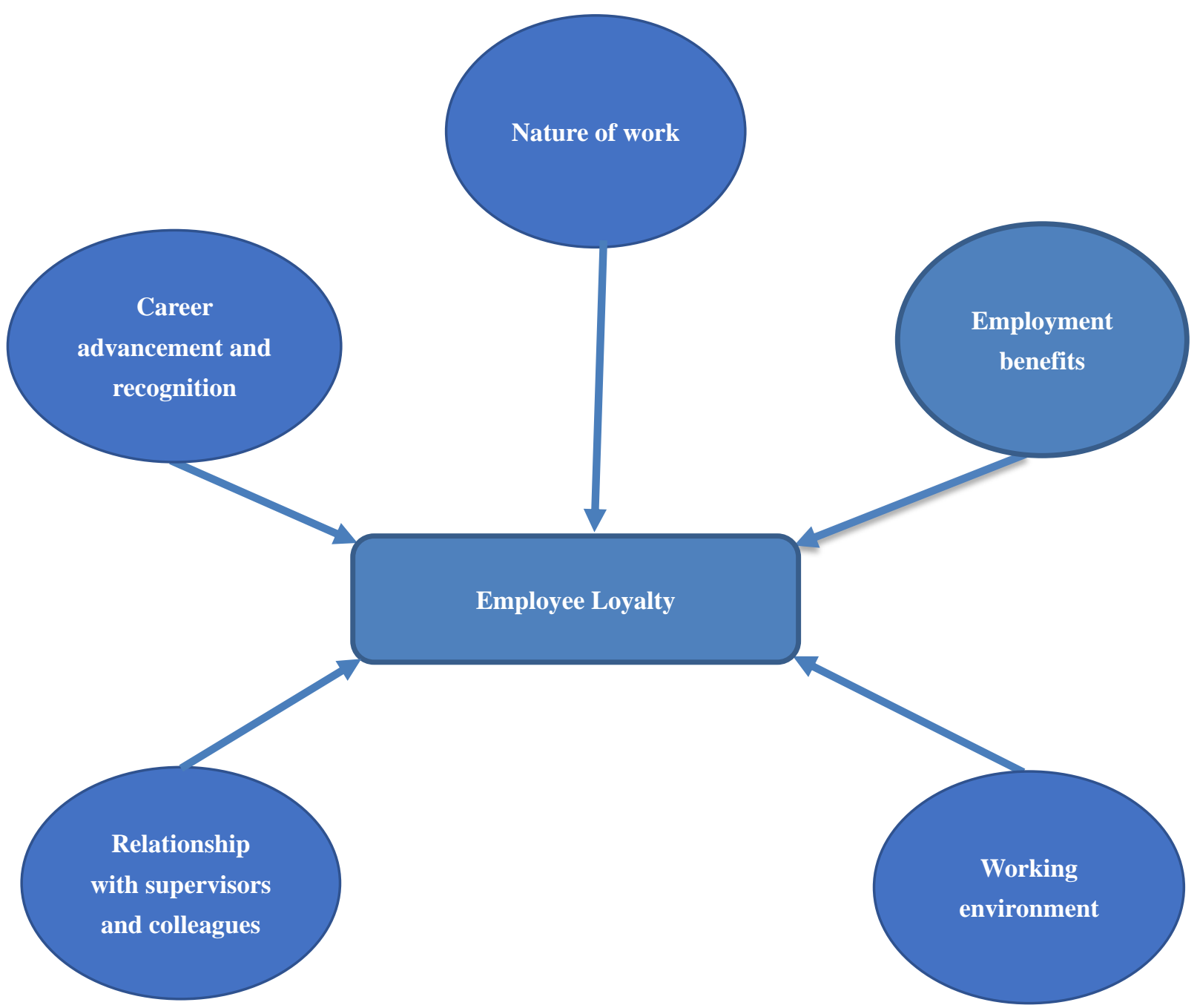

Figure 1. The five dimensions of Employee Loyalty

\subsubsection{Nature of Work}

This is a dimension that included factors linked to the work. They are founded on skill and knowledge. Issues included here are the importance of job responsibility, the level of challenge and excitement that an employee gets from doing the job, the quantity of the work that needs to be done, and the variety of tasks involved in doing the job.

\subsubsection{Career Advancement and Recognition}

This attribute is linked to elements representative of the potential for advancement in an individual's career. It speaks to the possibility for the individual to be part of a team that assists in solving problems, the potential that the employee will be promoted, and dealt with in a fair manner at work. Included in this item is also the possibility that the employee will receive adequate training and be allowed to conduct their tasks as independently as possible.

\subsubsection{Employment Benefits}

This factor is linked to issues related to the feeling that the job offers appropriate benefits such as adequate annual holidays, there are recreation activities that staff members can take part in, and the company will pay a fair annual bonus. It also looks at whether the company will pay salaries in a way that matches the job being done.

\subsubsection{Relationships with Colleges and Supervisors}

This attribute comprises elements linked to how strong the relationships with colleagues are. It concerns the 
manner in which activities that build relationships among members of staff are created, the sharing of ideas, and the management react with speed when there are issues that need to be resolved and when employees seek help from management.

\subsubsection{Working Environment}

Descriptors included under this element include the level of comfort employees feel when they are in the workplace. It looks at such issues as whether employees take pride in working for their departments. Another aspect under this factor is whether employees are pleased with the manner in which management in their department conducts itself.

According to Linz et al. (2015), firms reap the benefits of having loyal employees. This is a view also acknowledged by Abdullah et al. (2011) who says that when employees are loyal, they are actively engaged in helping their organizations meet their objectives and live up to the values of those organizations. The same author also notes that such employees do not usually go out to look for other jobs and will often turn down outside offers even when they are offered salaries that are slightly higher. For Rice et al. (2017) \& Guillon and Cezanne (2014), employee loyalty increases performance, through reducing turnover, boosting returns, improving quality, establishing trust among team members, and generally improving the reputation of the organization. Zatzick et al. (2015) agrees and notes that when the workforce is loyal, it is more likely to be committed the goals of the organization, and the employees themselves would reap the benefits emanating from reciprocated loyalty. Linz et al. (2015) report that the contribution of loyalty to earning for certain categories of employees has been seen to be higher than that of an added year of work experience or training.

\subsection{Workplace Bullying}

The idea of workplace bullying denotes an explicit or implicit aggressive behaviour directed at one or more individuals of an organization by other member (s) of the organization. This aggression can either be intended or unintended and could be seen as offensive, humiliating, and leading to a degree of distress to the person it is directed at (Glambek et al., 2018; Einarsen et al., 2019). Included in workplace bullying are abusive actions which would include words (spoken and in writing), behaviours, and gestures that may be damaging to the dignity, personality, and integrity of the individual to whom it is directed (Hirigoyen, 2015, p. 65; Pellegrini et al., 2018, p. 100).

A careful analysis of workplace bullying definitions indicates an agreement that duration and persistence are the main constructs of bullying. Nonetheless, Ariza-Montes et al. (2017) note that workplace bullying has a substantial mental component in the way it materialises. This is a view acknowledged by Rai and Agarwal (2017) who say that the persistency of unfitting behaviours with regards to repetition (at least one or two times a week), duration (at least for six months), and patterning (involving different types of behaviours), are some of the most notable elements of bullying.

Bullying can be classified into four categories: downward bullying, horizontal bullying, upward bullying, and inward bullying. Downward bullying is the leading type of bullying reported (Rutter \& Hine, 2005). According to Lee (2002), this kind of bullying is linked to the abuse of formal authority. In such cases, the perpetrator is emboldened by the power balance and makes the target weaker (Keashly, 2012). Horizontal bullying, on the other hand, denotes a situation where the perpetrator and the target area at the same rank within an organization (Casimir et al., 2012). The bullying is perpetrated by a colleague or a group of colleagues (De Cieri et al., 2019). For example, it has been suggested that with the aim of dealing with their sense of powerlessness within the healthcare rank order, nurses could become involved in displacement, a situation where aggression is transmitted to a colleague with less power such as a junior nurse (Laschinger et al., 2010). The idea of upward bullying speaks to a situation where the rank of the target is higher than that of the perpetrator (Casimir et al., 2012). This represents a theoretical concept as its practice could be damaging to employees, managers, and the organization in general (Branch et al., 2004). Inward bullying represents the kind of bullying perpetrated by outside elements such as visitors and patients (De Cieri et al., 2019).

Davenport et al. (2002) and Taylor (2012) introduce five dimensions of workplace bullying (Figure 2). The first is attacks in self-expression. As the name suggests, these dimensions included limiting opportunities for self-expression. Some of the specific behaviours exhibited under this dimension include threats (written or said) in public or privately, ongoing criticism of performance or private life, and denial of contact using gestures or looks. The second involves attacks on social relations. This dimension involves such elements like isolating from others of ignoring. The third dimension is attacked on reputation and involves talking badly behind someone's back, circulating groundless gossip, use of sarcasm and irony, forcing an individual to involve in tedious tasks, humiliating and wrong performance evaluation, ridiculing the decisions made by an individual, and using 
insulting names to call someone. The fourth dimension speaks to attacks on the quality of professional and personal life. This one includes items linked to being given low-value jobs, not being allocated tasks, mismatching qualifications and tasks, and instigating damages at home or in the workplace in such a way that leads to financial damage. The last dimension is linked to attacks on health. Included in this category of bullying are such acts as forcing an individual to do physically difficult tasks, threatening physical violence, and explicit sexual harassment.

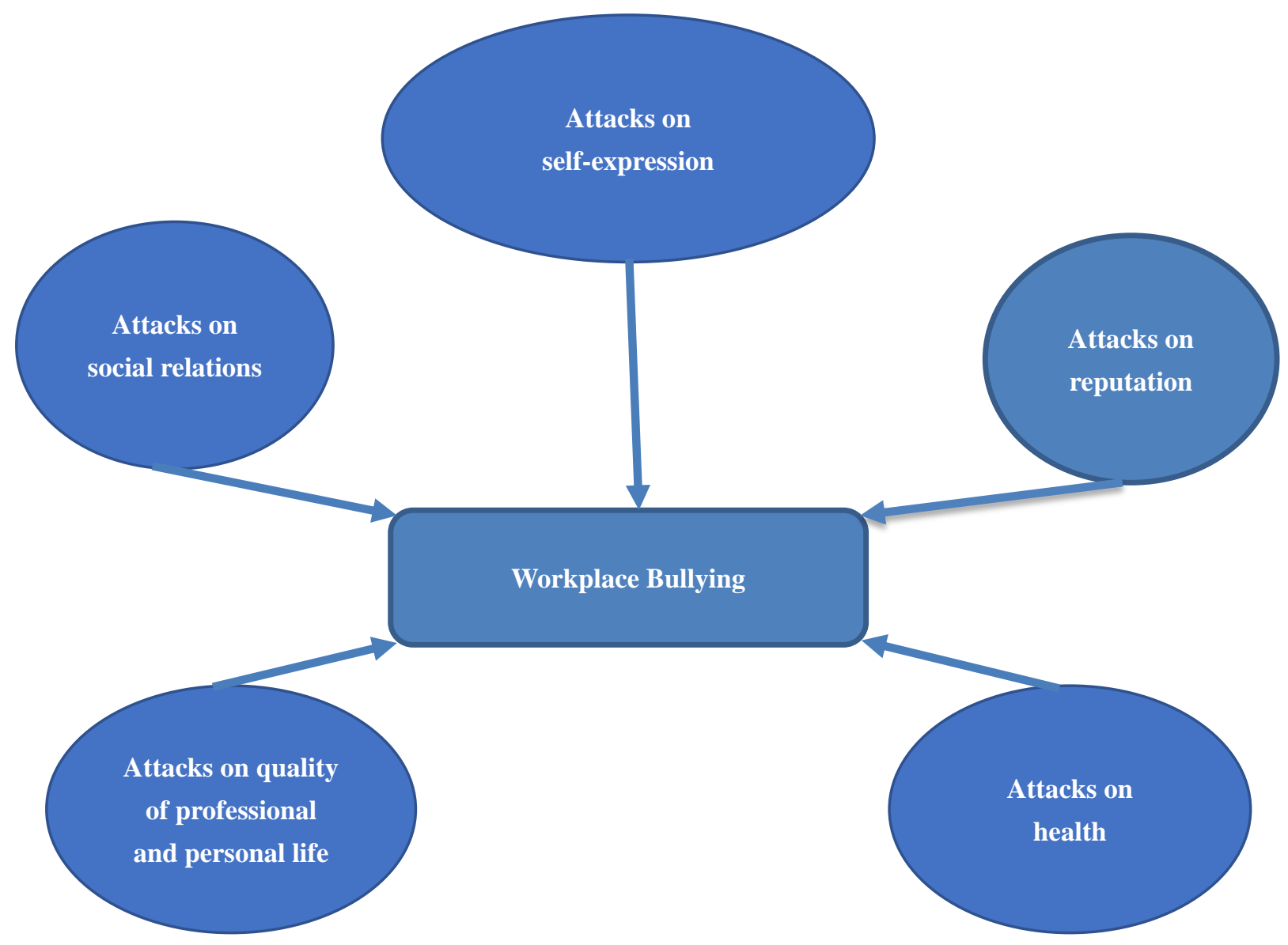

Figure 2. The five dimensions of workplace bullying

There are several reasons why an individual may not feel comfortable to report bullying in the workplace when it occurs (Chadwick \& Travaglia, 2017). Examples of such reasons could include lack of clarity about the process to be followed when reporting cases, the intricacy of the behaviours, fear of perceptions and possibility of losing a job, humiliation, the rank of the aggressor, and the character of the industry where the bullying occurs (Law et al., 2011; Sheehan \& Griffiths, 2011; Bryant et al., 2009; Cleary et al., 2009). Salin (2003) admits that the nature of health personnel work like nurses can shape the guidelines of social relationships in such a manner that bullying gets accepted, and perceived as something normal.

For both the individual who are victims of bullying and the organization, bullying can have a severe effect. For the individual, the consequences of bullying include lowered confidence, an escalation of negative emotions, depression, burnout, fatigue, stress, and anxiety (Cooper-Thomas et al., 2013).

From an organizational perspective, Jung and Yoon (2018) note that the result of bullying in the workplace could be a substantial economic loss as expressed through low performance (Harris et al., 2011), lower levels of production (Lewis \& Malecha, 2011), a reduction in levels of innovativeness (Mathisen et al., 2008), and an escalation of behaviours that are detrimental to productivity (Hershcovis et al., 2012).

Hsu et al. (2019) identify some studies which propose some methods of preventing discrimination at the 
organizational level. Examples include the introduction of a culture of anti-bullying (Duffy, 2009), specific policies that address bullying, (Sheehan et al., 2018), and mechanisms which make it easy for victims to report incidences of bullying in the workplace (Bentley et al., 2012). Understanding the literature forms a crucial initial step in addressing bullying in the workplace. This could be done through education and initiatives to raise awareness in the health sector as a strategy for prevention (Chadwick \& Travaglia, 2017).

The literature above has provided some basis on the direction in which debates about workplace bullying are moving. This will be helpful in meeting the aim of this study which is to examine the impact of workplace bullying on the loyalty of technical and specialist nurses.

\section{Methodology}

\subsection{Population and Sampling}

Total number of 792 specialist and technical nurses working in Menoufia university hospitals-Egypt composes the universe of the study. The survey, prepared as a tool of data collection, was handed to all specialist and technical nurses who accepted the study and 240 people (30.3\%) responded back. The surveys were implemented during the face-to-face interviews between 17 April and 26 June 2019. When the various defining features of the participants to the study were examined, it was found out that $66.7 \%$ of the participants were females and $33.3 \%$ of the them were males (see Table 1); $57.5 \%$ of the participants were specialist nursing and $42.5 \%$ of them were technical nursing. With regard to the ages of the participants, $66.7 \%$ of them less than 30 years, $26.7 \%$ from 30 to less than $40,5.8 \%$ from 40 to less than 50 and $0.8 \%$ from 50 to less than 60 years. Finally, With regard to the participants length of service in the hospital, $69.2 \%$ of them less than 10 years, $24.2 \%$ from 10 to less than 20 and $6.6 \%$ from 20 to less than 30 years.

Table 1. Descriptive characteristics of the respondents

\begin{tabular}{lcc}
\hline Characteristics & $\mathbf{N}$ & $\mathbf{\%}$ \\
\hline Gender: & & \\
\hline - Female & 160 & 66.7 \\
- Male & 80 & 33.3 \\
Age: & & \\
- Less than 30 years & 160 & 66.7 \\
- From 30 to less than 40 & 64 & 26.7 \\
- From 40 to less than 50 & 14 & 5.8 \\
- From 50 to less than 60 & 2 & 0.8 \\
Length of service in the hospital: & & \\
- Less than 10 years & 166 & 69.2 \\
- From 10 to less than 20 & 58 & 24.2 \\
- From 20 to less than 30 & 16 & 6.6 \\
- 30 and more & 0 & 0 \\
Position: & & \\
- Specialist nursing & 138 & 57.5 \\
- Technical nursing & 102 & 42.5 \\
\hline Total & $\mathbf{2 4 0}$ & $\mathbf{1 0 0}$ \\
\hline
\end{tabular}

\subsection{Data Collection Tool}

Workplace bullying was measured by asking the respondents to answer 31 items on a scale from 1 to 5 ( $1=$ strongly disagree, $5=$ strongly agree). Items were drawn from "Workplace Bullying in Higher Education: Faculty Experiences and Responses" survey (Taylor, 2012). The dimension of attacks on self-expression are evaluated with 8 questions, the dimension of attacks on social relations are evaluated with 4 questions, the dimension of attacks on reputation are evaluated with 10 questions, the dimension of attacks on quality of professional and personal life are evaluated with 6 questions, and the dimension of attacks on health are 
evaluated with 3 questions in the scale.

The scale used for measure employee loyalty was drawn from "Factors That Affect Employees Loyalty to An Organization: A Study of An Undergarment Factory in Nakhonpathom" (Kamnerdkarn, 2010). The scale is composed of a total of 19 items. The dimension of nature of work are evaluated with 4 questions, the dimension of career advancement and recognition are evaluated with 3 questions, the dimension of employment benefits are evaluated with 4 questions, the dimension of relationship with your supervisors and colleagues are evaluated with 4 questions, and the dimension of working environment are evaluated with 4 questions. All the items about employee loyalty are evaluated with five points Likert scale as in the workplace bullying scale.

\subsection{Data Analysis}

All statistical analyses were conducted via Statistical Package for The Social Science v20.0 (SPSS; http://spss.com). Descriptive analyses, validity and reliability analysis, correlation analysis, and multiple regression analysis were used in the data analyses.

\subsection{Validity and Reliability Analysis}

With the purpose of testing the validity and reliability of the scales used in the study, we benefited from factor analysis and Cronbach's Alpha coefficient. As a result of the reliability analysis on the workplace bullying scale, total Cronbach's Alpha reliability coefficient found out to be 0.76 . Six items decreasing the Cronbach's Alpha reliability coefficient were eliminated. As a result of the factor analysis on the workplace bullying scale, it was found out that the scale in this study exhibits a five-factor structure as in the study of Taylor (2012). However, five statements which have a disruptive effect on the factor structure and three items under the 0.50 factor load were excluded from the analysis. It was designated that this five-factor structure explains $54.7 \%$ of the total variance and the scale was included as a five-factor structure with attacks on self-expression, attacks on social relations, attacks on reputation, attacks on quality of professional and personal life and attacks on health.

As a result of the factor analysis implemented on the employee loyalty scale, total Cronbach's Alpha reliability coefficient found out to be 0.74 . Two items decreasing the Cronbach's Alpha reliability coefficient were eliminated. As a result of the factor analysis on the employee loyalty scale, it was found out that the scale in this study exhibits a five-factor structure as in the study of Kamnerdkarn (2010). However, two statements which have a disruptive effect on the factor structure and two items under the 0.50 factor load were excluded from the analysis. It was designated that this five-factor structure explains $53.2 \%$ of the total variance and the scale was included as a five-factor structure with nature of work, career advancement and recognition, employment benefits, relationship with your supervisors and colleagues, and working environment. Employee loyalty scale's total Cronbach's Alpha reliability coefficient was found out to be 0.91 .

\section{Results}

Considering the basic statistics about study variables in Table 2, it stands out that the attacks on health $(2.92 \pm$ $0.95)$ got the highest average and the attacks on quality of professional and personal life $(2.18 \pm 0.76)$ got the lowest average among the workplace bullying subdimensions.

Table 2. Means, standard deviation and correlation coefficients of research variables

\begin{tabular}{lccccccc}
\hline Variables & Mean & SD & $\mathbf{1}$ & $\mathbf{2}$ & $\mathbf{3}$ & $\mathbf{4}$ & $\mathbf{5}$ \\
\hline 1. Attacks on self-expression & 2.87 & 0.94 & 1 & & & & \\
2. Attacks on social relations & 2.51 & 0.81 & $0.309^{* * *}$ & 1 & & & \\
3. Attacks on reputation & 2.49 & 0.79 & $0.287^{* * *}$ & $0.249^{* * *}$ & 1 & & \\
$\begin{array}{l}\text { 4. Attacks on quality of professional } \\
\quad 2.18\end{array}$ & 0.76 & $0.208^{* *}$ & $0.210^{* *}$ & $0.214^{* *}$ & 1 & \\
$\quad$ and personal life & & & & & & & \\
5. Attacks on health & 2.92 & 0.95 & $0.296^{* *}$ & $0.258^{* *}$ & $0.267^{* *}$ & $0.272^{* *}$ & 1 \\
6. Employee loyalty & 2.68 & 0.84 & $-0.335^{* *}$ & $-0.249^{* *}$ & $-0.298^{* *}$ & $-0.239^{* *}$ & $-0.461^{* *}$ \\
\hline
\end{tabular}

SD: Standard Deviation, ${ }^{* *}$ Correlation is significant at 0.01 (two-tailed).

It can be said that the perception of the specialist and technical nurses about their loyalty ( $2.68 \pm 084)$ variable is moderate. The correlations between the subgroups of the workplace bullying are positively low and moderate 
$(0.208 \leq \mathrm{r} \leq 0.309)$. The correlations between the subgroups of workplace bullying and employee loyalty are negatively low and moderate $(-0.461 \leq \mathrm{r} \leq-0.239)$.

Multivariate regression analysis was conducted with the purpose of revealing the effects of subgroups of workplace bullying (attacks on self-expression, attacks on social relations, attacks on reputation, attacks on quality of professional and personal life, and attacks on health) on the employee loyalty. Being Durbin Watson coefficient of the formed regression model below 2.5 coefficient and the coefficient of Variance Inflation Factor (VIF) being less than 10 show that there is no multiple connection and autocorrelation (Hair, Anderson, and Tatham 1998). Statistical estimates about the regression model indicate that they are significant and usable ( $\mathrm{F}=$ 36.102 ; $\mathrm{P}<0.01$ ). Subdimensions of the workplace bullying explain the $23.8 \%$ of the total variance on the specialist and technical nurses' loyalty all together. Workplace bullying's each five subdimensions shows a negative relation with the specialist and technical nurses' loyalty. When the t-test results of regression coefficient significance in the regression model are examined, increasing of the attacks on self-expression $(\mathrm{t}=-4.819 ; \mathrm{P}<$ $0.01)$, attacks on social relations $(\mathrm{t}=-4.111 ; \mathrm{P}<0.01)$, attacks on reputation $(\mathrm{t}=-3.749 ; \mathrm{P}<0.01)$ and attacks on health $(\mathrm{t}=-6.080 ; \mathrm{P}<0.01)$ levels decreases the perception of specialist and technical nurses' loyalty. According to that, as the levels of the attacks on self-expression, attacks on social relations, attacks on reputation, and attacks on health of specialist and technical nurses increase, the perceptions of their loyalty will decrease. According to the standardized regression coefficient $(\beta)$, the relevant significant order of the precursor variables on the specialist and technical nurses' loyalty is such as attacks on health $(\beta=-0.341)$, attacks on self-expression $(\beta=-0.324)$, attacks on social relations $(\beta=-0.267)$, attacks on reputation $(\beta=-0.216)$, and attacks on quality of professional and personal life $(\beta=-0.088)$ (Table 3).

Table 3. Multiple regression analysis results

\begin{tabular}{|c|c|c|c|c|c|c|}
\hline Variable & B & Std. Error & $\boldsymbol{\beta}$ & $\mathbf{t}$ & $\mathbf{P}$ & VIF \\
\hline (Constant) & 3.945 & 0.151 & & 24.612 & 0.000 & \\
\hline - Attacks on self-expression & -0.314 & 0.042 & -0.324 & $-4.819^{*}$ & $<0.001$ & 1.29 \\
\hline - Attacks on social relations & -0.281 & 0.40 & -0.267 & $-4.111^{*}$ & $<0.001$ & 1.52 \\
\hline - Attacks on reputation & -0.194 & 0.59 & -0.216 & $-3.749^{*}$ & $<0.001$ & 1.44 \\
\hline $\begin{array}{l}\text { - Attacks on quality of professional } \\
\text { and personal life }\end{array}$ & -0.089 & 0.051 & -0.088 & -1.863 & 0.061 & 1.69 \\
\hline - Attacks on health & -0.298 & 0.041 & -0.341 & $-6.080^{*}$ & $<0.001$ & 1.18 \\
\hline
\end{tabular}

\section{Discussion and Conclusion}

From this study, it has been noted that scholars agree that bullying in the workplace is a serious matter that can cost the economy billions of dollars each year (Edwards \& Blackwood, 2017). It has also been noted that workplace bullying does not only affect the target of the attacks; it also impacts the organization they work for (De Cieri et al., 2019). However, for professionals in the human resources office, this is one of the most challenging areas to manage (Catley et al., 2017; De Cieri et al., 2019).

Spagnoli and Balducci (2017) report that empirical research has concluded that there is a link between WPB and higher degrees of mental distress (Agervold \& Mikkelsen, 2004), lack of organizational commitment (Hoel \& Cooper, 2000), deterioration in general health (Hoel \& Cooper, 2000; Vignoli et al., 2015), lower job satisfaction (Arenas et al., 2015), and an escalation in the level of absenteeism (Hoel \& Cooper, 2000). Organizations that ignore bullying are also negatively affected. For instance, employees who find themselves being targeted tend to take more days off, leave the company to find work elsewhere, report that expectations of task performance are not clear, show decreased motivation, work satisfaction, and commitment than their colleagues who are not targeted by bullies (Agervold \& Mikkelsen, 2004; Cooper-Thomas et al., 2013).

An examination of the literature on workplace bullying is examined, it becomes clear that downward bullying is the most common form of WPB in the field of health, especially among nurses (De Cieri et al., 2019). One may 
argue that for employees in this sector to deal with their disempowerment; nurses may get involved in displacement. This is a situation where they redirect their frustration to a less powerful colleague (Laschinger et al., 2010; De Cieri et al., 2019). Some of the research dealing with aggression and incivility have come up with proof of conduct that includes bullying from outside sources like visitors and patients (De Cieri et al., 2019). This can especially be the case in settings like mental health institutions and aged care facilities where the contact between nurses and patients is prolonged, the possibility for visitors of such patients to be perpetrators of inward bullying can be huge (De Cieri et al., 2019).

It was one of the aims of this study to determine is the perception of nurses with regards to bullying on the workplace impacts their level of loyalty. This was evaluated through the use of regression analysis on the data. Based on the regression model employed, it can be concluded the workplace bullying sub-dimensions provide a 23.8 percent explanation of the aggregate variance on employee loyalty. All five dimensions of WPB show a negative relation with employee loyalty.

As the participant's perception of bullying in the work setting increases, there is a statistical decrease in the perception of their loyalty. From the results of this study, it has been noted that there are a significant opposite direction and medium-level relation between employee loyalty and workplace bullying. These results are consistent with those done by several other scholars, including Pellegrini (2016) \& D'Cruz and Noronha (2012).

From the results obtained in this research, it was concluded that the nurses who participated feed that there is bullying in the workplace at a medium level. The levels of bullying perceptions in the workplace, as indicated by the participating nurses is as follows: attacks on health (2.92) and attacks on self-expression (2.87). It could be speculated that these high levels of prevalence may be a result of the role conflict and the stressful settings under which the nurses at Menoufia University hospitals work. In the category of attacks on health, the highest mean score was reported for physically intimidating bullying. These findings are not in agreement with those of Ganz et al. (2015).

One of the leading forms of workplace bullying behaviours among nurses is intimidation (Salin, 2015). With regards to attacks on self-expression, the highest item mean score in the category is for "being exposed to an unmanageable workload." The reason behind this could be linked to the kind of work that gets done at Menoufia University Hospitals. Other researchers have come to the conclusion that when a workload is perceived to be excessive, it can lead to nurses being exposed to behaviours linked to bullying (Ganz et al., 2015; Karatza et al., 2016). The leading forms of workplace bullying behaviours in such contexts are identified by Salin (2015): withholding information, giving employees undermining tasks, and attempting to break the confidence of the employee.

The workplace bullying level for attacks on social relations is medium at 2.51. Salin (2015) reports that one of the most common types of workplace bullying behaviours among nurses is exclusion. The workplace bullying level for attacks on reputation is also medium at 2.49 when it comes to nurses at Menoufia university hospitals.

Attacks on quality of professional and personal life are the meaningless sub-dimension in this study. It has the lowest average at 2.18. This dimension is mostly linked to bullying using tasks as a tool (Davenport et al., 2002, p. 37; Taylor, 2012, p. 21). The reason why this dimension is low can be interpreted to mean that the nurses believe that their jobs are meaningful and they are conscious of their contribution to meeting the objectives of the institution (Ozer et al., 2017). In the study conducted by Johnson and Rea (2009), the most negative behaviour noted by participants was "Someone withholding information which affects your performance" was the most frequent negative behaviour."

From a study that used data linked to 151,347 obtained from 136 articles, with a total of 60 samples, Spector, Zhou and Che (2014) came to the conclusion that nurses who believe that they have been victims of bullying in the workplace constitute 39 percent of the workforce (De Cieri et al., 2019). Rege (2017) cites numbers provided by the Pittsburgh-based Select International Healthcare which indicated that 85 percent of nurses reported that they had suffered abuse from a fellow nurse and about one-third of nurses have considered leaving the profession altogether because of bullying.

A study conducted by Berry et al. (2012) arrived at the conclusion that the higher bullying incidents reported among nurses were linked to higher impairment in intellectual status, lower output and poor handling of the workload. A study conducted by Gates et al. (2016) concluded that poor communication and support were linked to WPB (Wanga \& Hsieh, 2016). The same scholars report that when nurses are victims of bullying, it becomes a challenge for them to communicate with visitors and patients, generally fail to offer emotional support, and tend to feel detached from their colleagues and patients. This is a view supported by Al-Ghabeesh and Qattom (2019) who notes that workplace bullying has an adverse impact on the emotional well-being and productivity of nurses 
and creates a longing to abandon their professions. In instances were bullying effects the competency of nurses, such nurses can make mistakes such as giving employees the wrong medication (Al-Ghabeesh \& Qattom, 2019). This is a view in agreement with the observations of Roche et al. (2010), who reports that all kinds of violence were associated with delayed administration of medication.

It is the belief of Al-Ghabeesh and Qattom (2019) that organizations that want to decrease incidences of bullying in the workplace should take action such as the introduction of training programs for both the nurses and managers. This type of training should include such issues as anger management, improvement in communication skills, and conflict management. It is also important to have clear institutional policies that address the violence and workplace bullying and all employees need to be encouraged to report all incidents. Al-Ghabeesh and Qattom (2019) believes that boosting the capabilities of employees and promoting their communication capabilities using training programs may result in a decrease of violence in the workplace and its impact on members of staff (Al-Ghabeesh \& Qattom, 2019).

It is concluded that the perception of the nursing staff at Menoufia University Hospitals about their loyalty variable is medium-level (2.68). According to Peretti (2005, p. 110), employee loyalty is an expression of the "significant length of service in the company, very little tendency to seek or examine outside job offers and, generally, a strong sense of belonging."

Rice et al. (2017) report that in the hospitals and healthcare contexts, there are a number of wide-ranging labour-market elements, the specific nature of an organization, different employee attributes, ad characteristics of patients which come together to impact such outcomes like intentions to leaves, job satisfaction (McKillop \& Minnes, 2011), and the health outcomes of employees (Siegrist, 1996). It is these employee level affects that later become precursors for the effective performance of an organization and care for patients. This is a view supported by Guillon and Cezanne (2014) who say that elements that include, but are not limited to, an employee's role engagement, commitment to the organization, dedication to the task, and loyalty are crucial with regards to the how healthcare organizations perform when it comes to treating their patients.

Based on the results of this study, when the participants' perception of workplace bullying increases, their loyalty perceptions statistically decreases. It is on this basis that it can be suggested that managers in healthcare institutions should do everything in their power to prevent the bullying of employees in the workplace so that they can improve their loyalty. Such managers should understand that bullying involves as conflict at a personal level (De Cieri et al., 2019), a reduction in innovativeness (Mathisen et al., 2008), job stressors, undesirable environment settings (Notealers et al., 2013), adverse feelings (Vie et al., 2012), and reduced motivation (Salin, 2003). All these undesirable consequences can be alleviated by determining the factors that lead to bullying, deciding what needs to be done to prevent it and creating an environment that is safe.

While some conclusions have been drawn from this study, there are limitations to the generalizability of this study. For example, the sample is from a single hospital: Menoufia University Hospitals-Egypt. It is advisable that future studies should consider using larger samples so as to increase the study's generalizability.

\section{References}

Abdullah, R., Musa, M., Zahari, H., Rahman, R., \& Khalid, K. (2011). The study of employee satisfaction and its effects on loyalty in hotel industry in Klang Valley - Malaysia. International Journal of Business and Social Science, 2(3), 147-155.

Agervold, M., \& Mikkelsen, E. G. (2004). Relationship between bullying, psychological work environment and individual stress reactions. Work and Stress, 18(4), 336-361. https://doi.org/10.1080/02678370412331319794

Ahmad, S., Kalim, R., \& Kaleem A. (2017). Academics' perceptions of bullying at work: insights from Pakistan. International Journal of Educational Management, 31(2), 204-220. https://doi.org/10.1108/IJEM10-2015-0141

Al-Ghabeesh, S., \& Qattom, H. (2019). Workplace bullying and its preventive measures and productivity among emergency department nurses. BMC Health Services Research, 19(445), 1-9. https://doi.org/10.1186/s12913-019-4268-x

Arenas, A., Giorgi, G., Montani, F., Mancuso, S., Fiz Perez, J., Mucci, N., \& Arcangeli, G. (2015). Workplace bullying in a sample of Italian and Spanish employees and its relationship with job satisfaction, and psychological well-being. Frontiers in Psychology, 6(1912), 1-10. https://doi.org/10.3389/fpsyg.2015.01912 
Ariza-Montes, A., Arjona-Fuentes, J. M., Law, R., \& Han, H. (2017). Incidence of workplace bullying among hospitality employees. International Journal of Contemporary Hospitality Management, 29(4), 1116-1132. https://doi.org/10.1108/IJCHM-09-2015-0471

Balducci, C., Alfano, V., \& Fraccaroli, F. (2009). Relationships between mobbing at work and MMPI-2 personality profile, posttraumatic stress symptoms, and suicidal ideation and behavior. Violence and Victims, 24(1), 52-67. https://doi.org/10.1891/0886-6708.24.1.52

Bentley, T. A., Catley, B., Cooper-Thomas, H., Gardner, D., O’Driscoll, M. P., Dale, A., \& Trenberth, L. (2012). Perceptions of workplace bullying in the New Zealand travel industry. Tourism Management, 33(2), 351-360. https://doi.org/10.1016/j.tourman.2011.04.004

Berry, P. A., Gillespie, G. L., Gates, D., \& Schafer, J. (2012). Novice nurse productivity following workplace bullying. J Nurs Scholarsh, 44(1), 80-87. https://doi.org/10.1111/j.1547-5069.2011.01436.x

Branch, S., Sheehan, M., Barker, M., \& Ramsay, S. (2004). Perceptions of Upwards Bullying: An Interview Study. 4th International Conference on Bullying and Harassment in the Workplace, At Bergen, Norway.

Broome, B. S., \& Williams-Evans, S. (2011). Bullying in a caring profession: reasons, results, and recommendations. Journal of Psychosocial Nursing \& Mental Health Services, 49(10), 30-35. https://doi.org/10.3928/02793695-20110831-02

Bryant, M., Buttigieg, D., \& Hanley, G. (2009). Poor bullying prevention and employee health: some implications. International Journal of Workplace Health Management, 2(1), 48-62. https://doi.org/10.1108/17538350910946009

Casimir, G., McCormack, D., Djurkovic, N., \& Nsubuga-Kyobe, A. (2012). Psychosomatic model of workplace bullying: Australian and Ugandan schoolteachers. Employee Relations, 34(4), 411-428. https://doi.org/10.1108/01425451211236841

Catley, B., Blackwood, K., Forsyth, D., Tappin, D., \& Bentley, T. (2017). Workplace bullying complaints: lessons for "good HR practice". Personnel Review, 46(1), 100-114. https://doi.org/10.1108/PR-042015-0107

Chadwick, S., \& Travaglia, J. (2017). Workplace bullying in the Australian health context: a systematic review. Journal of Health Organization and Management, 31(3), 286-301. https://doi.org/10.1108/JHOM-09-2016-0166

Chen, C. (2006). Job satisfaction, organizational commitment, and flight attendants' turnover intentions: a note. Journal of Air Transport Management, 12(5), 274-276. https://doi.org/10.1016/j.jairtraman.2006.05.001

Cleary, M., Hunt, G. E., Walter, G., \& Robertson, M. (2009). Dealing with bullying in the workplace: toward zero tolerance. Journal of Psychosocial Nursing and Mental Health Services, 47(12), 34-41. https://doi.org/10.3928/02793695-20091103-03

Cooper-Thomas, H., Gardner, D., O'Driscoll, M., Catley, B., Bentley, T., \& Trenberth, L. (2013). Neutralizing workplace bullying: the buffering effects of contextual factors. Journal of Managerial Psychology, 28(4), 384-407. https://doi.org/10.1108/JMP-12-2012-0399

Cowan, R. L., \& Salin, D. (2015). Human resource professionals' perceptions of workplace bullying from across the globe. paper presented at the Academy of Management Annual Meeting Proceedings, Vancouver, BC. [Google Scholar]. https://doi.org/10.5465/ambpp.2015.11035symposium

D'Cruz, P., \& Noronha, E. (2012). Clarifying my world: identity work in the context of workplace bullying. The Qualitative Report, 17(8), 1-29.

Davenport, N., Schwartz, R. D., \& Elliott, G. P. (2002). Mobbing: emotional abuse in the American workplace. London: Civil Society Publishing.

De Cieri, H., Sheehan, C., Donohue, R., Shea, T., \& Cooper, B. (2019). Workplace bullying: an examination of power and perpetrators. Personnel Review, 48(2), 324-341. https://doi.org/10.1108/PR-02-2018-0057

Duffy, M. (2009). Preventing workplace mobbing and bullying with effective organizational consultation, policies and legislation. Consulting Psychology Journal: Practice and Research, 61 (3), 242-262. 
https://doi.org/10.1037/a0016578

Edwards, M., \& Blackwood, K. M. (2017). Artful interventions for workplace bullying: exploring forum theatre. Journal of Workplace Learning, 29(1), 37-48. https://doi.org/10.1108/JWL-05-2016-0035

Einarsen K., Salin, D., Einarsen, S. V., Skogstad, A., \& Mykletun, R. J. (2019). Antecedents of ethical infrastructures against workplace bullying: The role of organizational size, perceived financial resources and level of high-quality HRM practices. Personnel Review, 48(3), 672-690. https://doi.org/10.1108/PR-10-2017-0303

Ganz, F. D., Levy, H., Khalaila, R., \& Raanan, O. (2015). Bullying and Its Prevention Among Intensive Care Nurses. Journal of Nursing Scholarship, 47(6), 505-5011. https://doi.org/10.1111/jnu.12167

Georgakopoulos, A., \& Kelly M. (2017). Tackling workplace bullying: A scholarship of engagement study of workplace wellness as a system. International Journal of Workplace Health Management, 10(6), 450-474. https://doi.org/10.1108/IJWHM-11-2016-0081

Glambek, M., Skogstad, A., \& Einarsen, S. (2018). Workplace bullying, the development of job insecurity and the role of laissez-faire leadership: a two-wave moderated mediation study. Work \& Stress, 32(3), 297-312. https://doi.org/10.1080/02678373.2018.1427815

Guillon, O., \& Cezanne, C. (2014). Employee loyalty and organizational performance: a critical survey. Journal of Organizational Change Management, 27(5), 839-850. https://doi.org/10.1108/JOCM-02-2014-0025

Hair, J. F., Anderson, R. E., \& Tatham, R. L. (1998). Multivariate data analysis (5th ed.). New Jersey: Prentice Hall.

Harris, K. J., Harvey, P., \& Kacmar, K. M. (2011). Abusive supervisory reactions to coworker relationship conflict. The Leadership Quarterly, 22(5), 1010-1023. https://doi.org/10.1016/j.leaqua.2011.07.020

Hershcovis, M. S., Reich, T. C., Parker, S. K., \& Bozeman, J. (2012). The relationship be-tween workplace aggression and target deviant behavior: the moderating roles of power and task interdependence. Work \& Stress, 26(1), 1-20. https://doi.org/10.1080/02678373.2012.660770

Hirigoyen, M. (2015). Mal-estar no trabalho: redefinindo o assédio moral. Missouri: Bertrand.

Hoel, H., \& Cooper, C. (2000). Destructive Conflict and Bullying at Work. Manchester: Manchester School of Management.

Hsu, F. S., Liu, Y., \& Tsaur, S. H. (2019). The impact of workplace bullying on hotel employees' wellbeing: Do organizational justice and friendship matter? International Journal of Contemporary Hospitality Management, 31(4), 1702-1719. https://doi.org/10.1108/IJCHM-04-2018-0330

Ibrahim, M., \& Al Falasi, S. (2014). Employee loyalty and engagement in UAE public sector. Employee Relations, 36(5), 562-582. https://doi.org/10.1108/ER-07-2013-0098

Johnson, S. L., \& Rea, R. E. (2009). Workplace bullying: concerns for nurse leaders. J Nurs Adm, 39(2), 84-90. https://doi.org/10.1097/NNA.0b013e318195a5fc

Jung, H. S., \& Yoon, H. H. (2018). Understanding workplace bullying: Its effects on response and behavior in the hospitality industry. International Journal of Contemporary Hospitality Management, 30(3), 1453-1471. https://doi.org/10.1108/IJCHM-01-2017-0002

Kamnerdkarn, S. (2010). Factors That Affect Employees Loyalty to An Organization: A Study of An Undergarment Factory in Nakhonpathom. Bangkok: Language Institute, Thammasat University.

Karatza, C., Zyga, S., Tziaferi, S., \& Prezerakos, P. (2016). Workplace bullying and general health status among the nursing staff of Greek public hospitals. Ann Gen Psychiatry, 15(1), 7. https://doi.org/10.1186/s12991-016-0097-z

Keashly, L. (2012). Workplace and gender: it's complicated. in Fox, S., \& Lituchy, T. (Eds), Gender and the Dysfunctional Workplace. Edward Elgar, Cheltenham, pp. 78-95.

Laschinger, H. K. S., Grau, A. L., Finegan, J., \& Wilk, P. (2010). New graduate nurses' experience of bullying and burnout in hospital settings. Journal of Advanced Nursing, 66(12), 2732-2742. https://doi.org/10.1111/j.1365-2648.2010.05420.x

Law, R. D., Maureen, F., Tuckey, M. R., \& Dormann, C. (2011). Psychological safety climate as a lead indicator of workplace bullying and harassment, job resources, psychological health and employee 
engagement. Accident Analysis \& Prevention, 43(5), 1782-1793. https://doi.org/10.1016/j.aap.2011.04.010

Lee, D. (2002). Gendered workplace bullying in the restructured UK civil service. Personnel Review, 31(2), 205228. https://doi.org/10.1108/00483480210416874

Lewis, P. S., \& Malecha, A. (2011). The impact of workplace incivility on the work environment, manager skill, and productivity. The Journal of Nursing Administration, 41(1), 41-47. https://doi.org/10.1097/NNA.0b013e3182002a4c

Linz, S., Good, L. K., \& Busch, M. (2015). Promoting worker loyalty: an empirical analysis. International Journal of Manpower, 36(2), 69-191. https://doi.org/10.1108/IJM-06-2013-0129

Lu-Ming, T., \& Jui-Yun, W. (2017). How can financial organizations improve employee loyalty? The effects of ethical leadership, psychological contract fulfillment and organizational identification. Leadership \& Organization Development Journal, 38(5), 679-698. https://doi.org/10.1108/LODJ-07-2015-0142

Mathisen, G. E., Einarsen, S., \& Mykletun, R. (2008). The occurrences and correlates of bullying and harassment in the restaurant sector. Scandinavian Journal of Psychology, 49(1), 59-68. https://doi.org/10.1111/j.1467-9450.2007.00602.x

McKillop, J. M., \& Minnes, P. (2011). Occupational satisfaction, strain, and intention to quit among direct care providers assisting individuals with developmental disabilities. Journal on Developmental Disabilities, 17(1), 1-8.

Notealers, G., Baillien, E., DeWitte, H., Einarsen, S., \& Vermunt, J. (2013). Testing the strain hypothesis of the demand control model to explain severe bullying at work. Economic and Industrial Democracy, 34(1), 69-87. https://doi.org/10.1177/0143831X12438742

Ozer, O., Ugurluoglu, O., Saygili, M., \& Songur, C. (2017). The impact of work alienation on organizational health: A field study in health sector. International Journal of Healthcare Management, 12(1), 18-24. https://doi.org/10.1080/20479700.2017.1312804

Pellegrini, P. G. (2016). Assédio moral no trabalho e repercussões na estrutura e dinâmica familiars (Unpublished master's thesis). Universidade Federal de Santa Catarina, Florianópolis.

Pellegrini, P. G., Gonçalves, J., \& Tolfo, S. (2018). Repercussions of workplace bullying on marital relationships. Qualitative Research in Organizations and Management: An International Journal, 13(1), 98-120. https://doi.org/10.1108/QROM-10-2016-1431

Peretti, J. M. (2005). Dictionnaire des ressources humaines, Paris: Vuibert.

Rai, A., \& Agarwal, U. A. (2017). Exploring the process of workplace bullying in Indian organizations: A grounded theory approach. South Asian Journal of Business Studies, 6(2), 247-273. https://doi.org/10.1108/SAJBS-07-2016-0067

Rai, A., \& Agarwal, U. A. (2018a). A review of literature on mediators and moderators of workplace bullying: Agenda for future research. Management Research Review, 41(1), 822-859. https://doi.org/10.1108/MRR-05-2016-0111

Rege, A. (2017). 8 things to know about nurse bullying. Paper presented at the 11 th annual meeting for the Becker's Hospital Review, Hyatt Regency, Chicago, Tuesday, April 18th 6-9.

Rice, B., Knox, K., Rice, J., Martin, N., Fieger, P., \& Fitzgerald, A. (2017). Loyal employees in difficult settings: The compounding effects of inter-professional dysfunction and employee loyalty on job tension. Personnel Review, 46(8), 1755-1769. https://doi.org/10.1108/PR-05-2016-0124

Roche, M., Diers, D., Duffield, C., \& Catling-Paull, C. (2010). Violence toward nurses, the work environment, and patient outcomes. J Nurs Scholarsh, 42(1), 13-22. https://doi.org/10.1111/j.1547-5069.2009.01321.x

Rutter, A., \& Hine, D. (2005). Sex differences in workplace aggression: an investigation of moderation and mediation effects. Aggressive Behavior, 31(3), 254-270. https://doi.org/10.1002/ab.20051

Salin, D. (2003). Ways of explaining workplace bullying: a review of enabling, motivating and precipitating structures and processes in the work environment. Human Relations, 56(10), 12131232. https://doi.org/10.1177/00187267035610003

Salin, D. (2015). Risk factors of workplace bullying for men and women: the role of the psychosocial and 
physical work environment. Scandinavian Journal of Psychology, 56 (1), 69-77. https://doi.org/10.1111/sjop.12169

Salin, D., \& Notelaers, G. (2017). The effect of exposure to bullying on turnover intentions: the role of perceived psychological contract violation and benevolent behavior. Work \& Stress, 31(4), 355-374. https://doi.org/10.1080/02678373.2017.1330780

Sheehan, M., \& Griffiths, J. (2011). Understanding the context of workplace health management as it relates to workplace bullying. International Journal of Workplace Health Management, 4(1), 5-12. https://doi.org/10.1108/17538351111118563

Sheehan, M., McCabe, T. J., \& Garavan, T. N. (2018). Workplace bullying and employee outcomes: a moderated mediated model. The International Journal of Human Resource Management. https://doi.org/10.1080/09585192.2017.1406390

Siegrist, J. (1996). Adverse health effects of high-effort/low-reward conditions. Journal of Occupational Health Psychology, 1(1), 27-41. https://doi.org/10.1037/1076-8998.1.1.27

Silvestro, R. (2002). Dispelling the modern myth: Employee satisfaction and loyalty drive service profitability. International Journal of Operations \& Production Management, 22(1), 30-49. https://doi.org/10.1108/01443570210412060

Spagnoli, P., \& Balducci, C. (2017). Do high workload and job insecurity predict workplace bullying after organizational change? International Journal of Workplace Health Management, 10(1), 2-12. https://doi.org/10.1108/IJWHM-05-2016-0038

Taylor, S. K. (2012). Workplace Bullying in Higher Education: Faculty Experiences and Responses (Unpublished doctoral dissertation). University of, The Faculty of The Graduate School, The University of Minesota.

Turkyilmaz, A., Akman, G., Ozkan, C., \& Pastuszak, Z. (2011). Empirical study of public sector employee loyalty and satisfaction. Industrial Management \& Data Systems, 111(5), 675-696. https://doi.org/10.1108/02635571111137250

Vie, T. L., Glasø, L., \& Einarsen, S. (2012). How does it feel? Workplace bullying, emotions, and musculoskeletal complaints. Scandinavian Journal of Psychology, 53(2), 165-173. https://doi.org/10.1111/j.1467-9450.2011.00932.x

Vignoli, M., Guglielmi, D., Balducci, C., \& Bonfiglioli, R. (2015). Workplace bullying as a risk factor for musculoskeletal disorders: the mediating role of job-related psychological strain. BioMed Research International, Article ID 7126428, 8pp. https://doi.org/10.1155/2015/712642

Wanga,, M. L., \& Hsieh, Y. H. (2016). Do gender differences matter to workplace bullying? Work, 2016, 631-8. https://doi.org/10.3233/WOR-152239

Zabrodska, K., \& Kveton, P. (2013). Prevalence and forms of workplace bullying among university employees. Employee Responsibilities and Rights Journal, 25(2), 89-108. https://doi.org/10.1007/s10672-012-9210-x

Zatzick, C., Deery, S., \& Iverson., R. (2015). Understanding the determinants of who gets laid off: does affective organizational commitment matter? Human Resource Management, 54(6), 877-891. https://doi.org/10.1002/hrm.21641

\section{Copyrights}

Copyright for this article is retained by the author(s), with first publication rights granted to the journal.

This is an open-access article distributed under the terms and conditions of the Creative Commons Attribution license (http://creativecommons.org/licenses/by/4.0/). 